\title{
Uma análise quantitativa do processo de concorrência em compras públicas dos pregões da Prefeitura Municipal de Pelotas
}

\author{
Rodrigo Nobre Fernandez \\ Universidade Federal de Pelotas, Pelotas - RS, Brasil \\ Thaís Garcia Riba \\ Prefeitura Municipal de Pelotas, Pelotas - RS, Brasil
}

Este trabalho teve por objetivo avaliar quais fatores determinam a concorrência, medida pelo número de vencedores, em cada certame, das licitações realizadas pela Prefeitura Municipal de Pelotas. Analisou-se o período de 2016 a 2017, observando-se as licitações no formato de pregão presencial ou eletrônico, que visam à aquisição de bens e serviços comuns pela administração pública com o menor preço possível. Para atingir tal meta, construiu-se uma base de dados com informações referentes a 591 pregões disponíveis na página virtual do Tribunal de Contas do Estado do Rio Grande do Sul e aplicou-se o modelo de regressão de Poisson. Em suma, os resultados apontam que o valor do edital apresenta um efeito positivo no número de vencedores, sendo que o aumento de uma unidade dessa variável aumenta em média em $12 \%$ o número de ganhadores. Contudo, o fato de o certame apresentar pelo menos um item frustrado reduz, em média, em $30 \%$ o número de vencedores. Adicionalmente, verificou-se que o aumento de dois meses no tempo entre o lançamento e a homologação do edital acarreta, em média, um impacto positivo de aproximadamente $25 \%$ no número dos ganhadores. Esses achados podem sugerir que compras com valor mais elevado e com o prazo mais dilatado podem favorecer a administração pública no aumento da concorrência e consequentemente na obtenção de um preço unitário mais baixo.

Palavras-chave: pregões, licitação, regressão de Poisson

Códigos JEL: H41, H57, H83. 


\section{Competencia en las compras públicas: un análisis económico de las subastas del Municipio de Pelotas}

Este trabajo tuvo como objetivo evaluar qué factores determinan la competencia, medida por el número de ganadores en cada evento, de las licitaciones realizadas por el Ayuntamiento de Pelotas. El análisis se realizó para el período de 2016 a 2017, y fueron observadas las licitaciones en el formato de subasta presencial y de subasta electrónica, destinadas a la adquisición de bienes y servicios comunes por parte de la Administración Pública al menor precio posible. Para lograr este objetivo, se construyó una base de datos con información referente a 591 subastas disponibles en la página virtual del Tribunal de Cuentas del Estado de Rio Grande do Sul y se aplicó el modelo de regresión de Poisson. En resumen, los resultados demuestran que el valor del aviso público tiene un efecto positivo en el número de ganadores, de esa manera el aumento de una unidad de esta variable aumenta el número de ganadores en promedio en $12 \%$. Sin embargo, si el impacto del evento presenta al menos un artículo frustrado reduce el número de ganadores en promedio en $30 \%$. Adicionalmente, se comprobó que el incremento de dos meses en el tiempo entre el lanzamiento y la homologación del aviso público provoca, en promedio, un impacto positivo de aproximadamente $25 \%$ en el número de ganadores. Estos hallazgos pueden sugerir que las compras de mayor valor y mayor plazo pueden favorecer a la Administración Pública para incrementar la competición y consecuentemente obtener un precio unitario más bajo.

Palabras clave: subastas, licitación, regresión de Poisson

Códigos JEL: H41, H57, H83.

\section{A quantitative analysis of the competition process in public purchases of Pelotas' reverse auctions}

This work aimed to evaluate which factors determine the competition, measured by the winners' number in each event, of the public bids held by the Municipality of Pelotas. The analysis was conducted taking the period from 2016 to 2017, observing the bids in the presential or electronic reverse auction format, aimed at the acquisition of common goods and services by the Public Administration at the lowest possible price. To achieve this goal, a database was built with information referring to 591 reverse auctions sessions available on the virtual page of the Rio Grande do Sul Province Court of Accounts and the Poisson regression model was applied. In summary, the results show that the monetary value of the public bid has a positive effect on the number of winners, with the increase of one unit of this variable increasing the number of winners on average by $12 \%$. However, the impact of the contest has presented frustrated items reduces the number of winners on average by $30 \%$. Additionally, it was found that the two-month increase in the time between the launch and the approval of the public bid on average has a positive impact of approximately $25 \%$ on the number of winners. These findings may suggest that purchases with a higher value and with a longer term may favor Public Administration in increasing competition and consequently in obtaining a lower unit price.

Keywords: reverse auctions, bidding, Poisson regression

JEL Codes: H41, H57, H83. 


\section{Introdução}

A administração pública tem por importante atividade burocrática a realização de processos licitatórios para a aquisição de bens, serviços e alienações, que atendam à sua demanda interna e também ao interesse público, de forma eficiente. Esses procedimentos, em geral, são regulamentados pela Lei no 8.666/93 e suas alterações, e devem obedecer aos princípios da legalidade, da impessoalidade, da moralidade, da publicidade e da eficiência, conforme artigo no 37 da Constituição Federal de 1988 (BRASIL, 1988).

Contudo, devido à morosidade presente nas diferentes modalidades licitatórias, criou-se o pregão, modalidade de compras públicas do tipo menor preço, que foi regulamentado inicialmente pela Medida Provisória no 2.026 de 2000, convertida na Lei $\mathrm{n}$ o 10.520 de 2002, visando a uma maior celeridade e economicidade em procedimentos licitatórios para a aquisição de bens e serviços comuns, sem limite de valor. Nessa mesma linha, com a publicação oficial do Decreto n 3.697 de 2000 , surgiu o pregão eletrônico, que tem a maior parte de seus trâmites realizados pela internet, o que possibilita a participação de um número maior de candidatos para dar lances. O último foi substituído pelos decretos no 5.450 de 2005 e n 10.024 de 2019 (BRASIL, 2000a, 2002a, 2002b, 2005, 2019).

Partindo do princípio de que os municípios, os estados e a União fazem utilização da modalidade licitatória do tipo pregão para a aquisição de bens e serviços comuns, de forma rápida e econômica, o presente trabalho teve por objeto de estudo analisar as compras públicas realizadas pela Prefeitura Municipal de Pelotas, sob essa modalidade, que considera primordial o menor preço, tanto em seu modo eletrônico, como no modo presencial, com ou sem registro de preços.

Dentro desse escopo, a análise quantitativa do processo de concorrência em compras públicas pode oferecer informações importantes, que estão alinhadas com a orientação da Lei № 12.529 de 2011, a qual dispõe, principalmente, sobre a prevenção e a repressão às infrações contra a ordem econômica; a livre concorrência; a defesa dos consumidores; e a repressão ao abuso do poder econômico (BRASIL, 2011). 
Dessa forma, este estudo apresenta as seguintes contribuições: i) avalia empiricamente os leilões referentes às compras públicas na modalidade de pregão para o Município de Pelotas, localizado na região sul do Estado do Rio Grande do Sul; ii) incrementa um estudo à literatura nacional, tendo em vista a escassez de trabalhos que avaliem quantitativamente as licitações; iii) embora a avaliação efetuada neste artigo refira-se a um município específico, a mesma pode ser útil para os gestores públicos e policymakers promoverem adequações e identificarem quais fatores são importantes para o sucesso da concorrência do certame.

Com esse propósito, tem-se como variável dependente o número de empresas vencedoras das licitações na modalidade de pregão (presencial e eletrônico). Essa variável é utilizada como uma proxy para concorrência no processo licitatório. Espera-se que, em um pregão em que tenham sido licitados $x$ itens, quanto mais o número de firmas vencedoras se aproxime de $x$, maior será a concorrência dentro desse concurso, implicando um menor preço para o ente público.

Para realizar essa tarefa, foram coletadas informações de 591 pregões no período de 2016 e 2017 do banco de dados da página virtual do Tribunal de Contas do Estado do Rio Grande do Sul (TCE/RS), denominada LicitaCon Cidadão ${ }^{1}$. A escolha desse intervalo temporal se deu pela obrigatoriedade do registro dos pregões na esfera municipal nessa plataforma a partir de 2016, fato previsto pela Resolução no 1.050 de $2015^{2}$ do Tribunal de Contas do Estado do Estado do Rio Grande do Sul (RIo GRANDE Do SUL, 2015).

Cabe salientar que a variável dependente assume somente valores discretos, inteiros e não negativos, sendo assim caracterizada como dado de contagem (FÁvERO; BELFIORE, 2017). Tendo em vista essa característica, para proceder a análise empírica, utilizou-se o modelo de regressão de Poisson. Esse estimador é mais adequado para o caso estudado quando comparado ao de Mínimos Quadrados Ordinários. Isso ocorre porque esse último presume a normalidade de variáveis dependentes contínuas, o que geralmente não ocorre com variáveis discretas, principalmente nas situações em que esses indicadores se concentram em um conjunto muito pequeno de valores (WOOLDRIDGE, 2010, p.723-766).

\footnotetext{
${ }^{1}$ Disponível em: http://www1.tce.rs.gov.br/aplicprod/f?p=50500:1:114335485586619

${ }^{2}$ A Resolução no 1.050/15 teve a redação alterada pela Resolução no 1.073/17, no sentido que modifica a data da obrigatoriedade (10 de dezembro de 2016) para outros jurisdicionados estaduais que não os municípios (RIO GRANDE DO SUL, 2015, 2017).
} 
Com base nas considerações propostas por Faria et al. (2011), Nóbrega (2015) e no relatório técnico da Controladoria Geral da União (2017), escolheram-se como variáveis independentes indicadores que poderiam auxiliar a explicar o número de vencedores, bem como o valor homologado da licitação, o valor unitário homologado, o valor estimado ou esperado, a diferença de tempo em dia(s) do lançamento do edital até a homologação dos vencedores e as variáveis dummies, sendo elas referentes ao setor da compra, à modalidade do pregão e à possibilidade de frustração de itens no processo licitatório.

Dentro desse escopo, os resultados apontam que o valor total (estimado e homologado) do edital apresenta um efeito positivo no número de vencedores. O aumento de uma unidade dessa variável acresce em média 12\% ao número de ganhadores. Um valor mais elevado pode ser decorrente de um número maior de itens licitados ou do alto valor dos objetos a serem comprados pelo ente público. Nesse sentido, um valor mais alto atrai um número maior de empresas para participarem do certame, aumentando a competição contratual.

Nesse mesmo âmbito, o valor unitário homologado não apresentou significância estatística nas regressões efetuadas. Esse resultado pode indicar que as empresas preferem participar de licitações em que o valor total é maior, independentemente do preço unitário do item.

Além disso, a diferença entre a data de lançamento do edital e a homologação do resultado final mostrou um efeito positivo, que pode indicar que o período entre a abertura do edital e a inscrição dos participantes propicia uma maior participação das firmas no processo licitatório. Contudo, o efeito do certame apresentar pelo menos um item frustrado reduz em média em $30 \%$ o número de vencedores. Também se verificou que objetos relacionados ao setor de educação apresentam um número maior de ganhadores, o que não acontece para os itens licitados para o setor de alimentação.

Por fim, este trabalho está estruturado em cinco seções, tendo início por esta breve introdução. Na segunda parte, faz-se um breve referencial teórico sobre a modalidade de pregão no âmbito das licitações. Em seguida, na terceira parte, apresenta-se a metodologia, os dados, as estatísticas descritivas e a estratégia empírica. E, posteriormente, analisam-se os resultados e encerra-se o trabalho com as considerações finais nas seções de números 4 e 5. 


\section{Pregões: uma modalidade de licitação}

São cinco as modalidades de licitação existentes no âmbito das compras públicas, estabelecidas pela Lei n.o 8.666 de 1993, denominadas como concorrência, tomada de preços, convite, concurso e leilão. Além disso, essa lei prevê casos de dispensa e de inexigibilidade de licitação (BRASIL, 1993).

Com a conversão na Lei o 10.520 de 2002 da medida provisória no 2.026 de 2000, que regulamenta a aquisição de bens e serviços comuns, sem limite de valor, foi criado o pregão, sob a forma presencial, que é a sexta modalidade licitatória, do tipo menor preço, e também a que mais se destaca por sua celeridade, economia e transparência. Em 2005, com a publicação oficial do Decreto no 5.450 e com a sua atualização em 2019, posta pelo Decreto $\mathrm{n}$ - 10.024, o pregão passa a poder também ser realizado na forma eletrônica, com uso de página virtual específica de internet, o que possibilitou maior participação de outros estados brasileiros no certame, além do Rio Grande do Sul (BRASIL, 2000a, 2002a, 2005, 2019).

Segundo Alencar (2006), na forma presencial, os participantes, de modo tradicional, comparecem ao órgão licitador na data e hora previamente determinada, e apresentam suas propostas e lances verbais. Já no pregão do tipo eletrônico, não há a presença física dos representantes das empresas licitantes, isso porque esse tipo de pregão utiliza recursos da tecnologia da informação, através de interligação via internet.

Essa modalidade contratual também pode contar com o sistema de registro de preços (SRP), que, apesar de não ser uma modalidade de licitação, é, segundo Silva e Brito (2017), um procedimento integrante. E uma das suas características é que o fornecedor deve cumprir com as condições estabelecidas no instrumento convocatório. E ainda, o SRP veio para facilitar a aquisição de produtos/serviços na administração pública, pois envolve uma transparência maior nos atos administrativos, contando também com outros benefícios, como: desnecessidade de dotação orçamentária (no momento da contratação), possibilidade de adesão à ata tanto por órgãos participantes quanto por não participantes do certame, entre outros. 
Em sua pesquisa, Pena, Felicidade e Monteiro (2010) evidenciam a eficiência e as vantagens do pregão eletrônico como meio de licitar perante as demais modalidades. É um modelo inovador para a administração pública e para as empresas, pois para sua utilização as organizações devem se adaptar às mudanças tecnológicas para participar dos certames virtuais e se manterem competitivas no mercado. Por se efetuar através da internet, essa nova forma de licitar torna-se célere, visto que o tempo gasto no pregão eletrônico é reduzido, além de transparente, por possibilitar que qualquer pessoa possa acompanhar o processo em tempo real.

Para Brandão (2016), a eficiência evidenciada na ferramenta de compra denominada pregão eletrônico estaria na inversão das fases durante a abertura da licitação, por permitir a análise das propostas cadastradas no sistema de compras antes da fase de habilitação, reduzindo o tempo da fase externa do certame. Outra característica importante, que traz vantagem financeira para a instituição pública, é a possibilidade de realizar disputa de lances em tempo real entre os fornecedores, conhecida como leilão reverso, bem como o uso de tecnologias da informação e internet, propiciando a ampliação da concorrência entre os fornecedores e o aumento da participação de pequenas empresas nos processos licitatórios, em razão do baixo custo operacional.

Nesse sentido, Faria et al. (2011), em seu estudo, analisaram a eficiência do pregão eletrônico nas compras públicas e identificaram suas vantagens e desvantagens. Para a realização do referido trabalho, foram escolhidas a Prefeitura Municipal de Viçosa, a qual utiliza o modelo presencial, e a Universidade Federal de Viçosa, que utiliza o modelo eletrônico. Assim, o objetivo dos autores era analisar custos e tempo gasto com licitações nos dois órgãos, benefícios e perdas que o modelo eletrônico de compra apresenta frente ao modelo presencial. Para atender ao objetivo do trabalho, os pesquisadores realizaram a análise descritiva dos dados e fizeram um teste de diferença de médias. A conclusão desse estudo foi que o pregão eletrônico é a modalidade de licitação mais vantajosa, pois apresentou menor tempo para finalização do processo, com chance de erro de 4,4\%, comprovando um potencial de redução mais significativo para tempo e preço. Contudo, o pregão presencial também se mostrou eficiente e, por isso, poderá ser utilizado pela Prefeitura de Viçosa até que essa tenha a estrutura necessária para a utilização do pregão eletrônico. 
Entretanto, mesmo com todas as vantagens existentes na modalidade de pregão, há importantes deficiências que foram observadas e apontadas por Azevedo (2011), como a falta de conhecimento sobre as características do produto, o que pode tornar o processo moroso e inadequado. Sob esse mesmo prisma, Dias (2014) também percebeu e revelou algumas deficiências do pregão eletrônico, entre elas a aquisição de bens e serviços de baixa qualidade. Mostrou que, quando há insuficiência da especificação técnica do objeto a ser licitado, isso pode levar o órgão da administração pública a realizar uma má compra. E como o pregão eletrônico é uma modalidade de licitação por menor preço, então é importante o detalhamento na descrição do objeto, a fim de afastar a compra de produtos e/ou serviços de baixa qualidade.

Comprovada a redução dos custos operacionais e a celeridade, Furtuna (2015) indica que ambas, advindas da simplificação do procedimento licitatório, na modalidade de pregão eletrônico, resultam na diminuição considerável dos preços finais contratados pela administração pública. Para o pesquisador, a maior vantagem do pregão eletrônico é a transparência de seus procedimentos, realizados por meio da internet. Isso porque possibilita ao cidadão o acompanhamento dos atos governamentais, o que é uma forma de tornar o controle fiscal mais efetivo por parte da sociedade, reduzindo os casos de corrupção em licitações públicas.

Nesse sentido, Faria et al. (2011), ao comparar o pregão eletrônico com o presencial, verificaram que é preciso atentar-se para o fato de que ambos os pregões possibilitam realizar uma compra com um preço menor que as demais modalidades licitatórias. Para os autores, por meio do pregão eletrônico, a estrutura de mercado dos processos licitatórios tende a passar de monopólios e oligopólios para mercado competitivo, o que faz com que as empresas não obtenham poder de decisão sobre o preço e a competição prevaleça na formação do preço final.

Nesse sentido, o relatório técnico desenvolvido pela Controladoria Geral da União (CGU), no ano de 2017, compila vários argumentos que defendem a necessidade de realizar o ajuste dos limites das modalidades licitatórias e também da elevação do limite para que se possa realizar o procedimento de dispensa de licitação. O documento se resume basicamente aos seguintes tópicos: i) do benefício do pregão eletrônico versus a dispensa; ii) do comparativo da celeridade processual; iii) do impacto da elevação dos 
limites da dispensa sobre as demais modalidades; iv) do comparativo com os limites de dispensa das estatais; e v) da evolução dos custos de pessoal na administração pública (CONTROLAdORIA GERAL DA UNIÃO, 2017).

Ainda, no supracitado texto, a CGU verificou que o custo final dos processos realizados sob a modalidade de pregão eletrônico é aproximadamente dez vezes maior do que aqueles realizados na modalidade de dispensa de licitação. Por essa razão, a referida controladoria indica que a forma de dispensa de licitação deveria estar disponível no texto da lei geral das licitações, nas demais modalidades a serem realizadas em meio eletrônico, de maneira extensiva a todos os entes e poderes. Essa medida possibilitaria à sociedade um amplo acesso às informações dos processos licitatórios, bem como os que dispensariam a licitação. Ademais, seria possível ter conhecimento dos fornecedores consultados e dos preços apresentados, além da possibilidade de participação de outros interessados além dos pesquisados. (CONTROLADORIA GERAL DA UNIÃO, 2017).

Ademais, Nóbrega (2015) destaca que, na licitação tradicional, o governo elabora o orçamento e usa para sua base uma série de tabelas referenciais. Ocorre que o governo não detém nenhuma informação sobre a estrutura de custo das empresas fornecedoras de bens e serviços comuns, o que culmina com desacertos e atrasos. Um outro problema recorrente em licitações, segundo o referido autor, é o "fetiche do menor preço", que não necessariamente significa a melhor proposta para o governo contratante. Na maioria das vezes, os preços propostos nas licitações são artificialmente pressionados para garantir a vitória no certame e acabam culminando com a má qualidade, abandono de obras ou excesso de aditivos.

Enfim, o que se percebe a partir da análise desses estudos é que, mesmo havendo ainda algumas dificuldades para a boa execução de um processo licitatório que resulte em compras públicas mais eficientes sob a modalidade de pregão, seja ele eletrônico ou presencial, ainda há muitas vantagens e grande eficácia no uso dessa modalidade em processos de compras públicas, quando comparada às demais.

O problema da assimetria de informação, que pode ocorrer entre licitantes e administrações públicas no ato de conduzir processos de compras para aquisição de bens e serviços comuns, configura-se uma dificuldade que pode ser amenizada ou até mesmo 
solucionada por meio de um maior detalhamento nas especificações técnicas de produtos a serem adquiridos. Assim como o uso de maior transparência para o acompanhamento público desses processos poderia causar uma diminuição em corrupções em licitações públicas.

\section{Metodologia}

\subsection{Dados}

Com o propósito de estimar a concorrência em serviços e compras públicas no Município de Pelotas, mais especificamente no período de 2016 e 2017, serão utilizadas informações referentes ao estado onde estão localizados os fornecedores ganhadores de pregões constantes na página virtual da Receita Federal, na qual foi feita consulta por CNPJ; além de informações específicas sobre cada pregão realizado pela Prefeitura Municipal de Pelotas, que podem ser acessadas por meio da página virtual do Tribunal de Contas do Estado do Rio Grande do Sul (TCE/RS), denominada LicitaCon Cidadão.

Dessa forma, foi constituída uma amostra ${ }^{3}$ composta por 591 licitações do tipo pregão, entre as quais 576 pregões são do tipo eletrônico e 15 pregões são do tipo presencial. Além disso, entre esses 591 pregões, 221 foram realizados no ano de 2016 e 370 foram realizados no ano de 2017. Também bens e serviços foram classificados em cinco setores, de acordo com o tipo de utilidade que possuem: saúde, alimentos, construção, educação e outros. Isso porque o tipo de bem ou serviço a ser contratado consiste em uma dummy, que poderá influenciar no resultado de um pregão.

É importante salientar que não foram incorporados a este trabalho os dados de pregões realizados por autarquias, câmara municipal, empresas públicas, sociedades anônimas, sociedades limitadas e consórcio administrativo, visto que, apesar de serem órgãos municipais, possuem administração própria e individualizada.

\footnotetext{
${ }^{3}$ Os dados utilizados nesta pesquisa foram atualizados até 30/10/2018.
} 
A análise empírica efetuada consiste em verificar a relação entre a concorrência, medida pelo número de ganhadores do pregão, e as características do processo licitatório na modalidade presencial e eletrônica.

Pode-se contextualizar essa relação por meio do seguinte exemplo: suponha que foi aberta uma licitação sob a modalidade de pregão (presencial ou eletrônico), que possui 30 itens para serem comprados para uso pelo órgão público licitante. Nesse caso, essa licitação poderá ter no mínimo 01 e no máximo 30 ganhadores. Por se tratar de pregão, menor preço é o critério a ser considerado primordial para cada fornecedor ganhar cada item licitado.

Considerando que o mercado competitivo é mais vantajoso quando comparado a outras estruturas de mercado ${ }^{4}$ e que a competição presente em processos licitatórios do tipo pregão faz com que os fornecedores ofertem seus bens e serviços pelo menor preço possível, um pregão com 30 itens e 30 ganhadores possui a probabilidade do menor preço possível (maior economicidade) quando comparado a um pregão que apresenta 30 itens e apenas 01 ganhador para todos esses itens.

Dessa forma, o principal critério a ser aplicado será considerar como variável dependente o número de ganhadores e como variáveis independentes a diferença de tempo em dias, o valor homologado, o valor unitário homologado e o valor estimado. Também foram incluídas dummies referentes ao ano, à modalidade da licitação e aos setores (tipos de bem ou serviço solicitados).

Essas variáveis se organizam da forma apresentada na Tabela 1:

\section{Tabela 1 | Variáveis utilizadas}

\section{Variável}

Número de ganhadores

Valor homologado vhomologado

\section{Descrição}

Refere-se ao número de ganhadores dos pregões (variável dependente).

Refere-se ao valor efetivo de cada pregão.

\footnotetext{
${ }^{4}$ Uma discussão detalhada sobre estrutura de mercados pode ser encontrada em: Mas-Collel, Whinston e Green (1995, p.405-411)
} 


\begin{tabular}{|c|c|c|}
\hline Variável & Legenda & Descrição \\
\hline Valor estimado & vestimado & $\begin{array}{l}\text { Refere-se ao valor estimado pela gestão pública ao } \\
\text { lançar o edital. }\end{array}$ \\
\hline Valor unitário & vunitario & $\begin{array}{l}\text { Refere-se ao valor total homologado dividido pelo } \\
\text { número de itens comprados na licitação. }\end{array}$ \\
\hline $\begin{array}{l}\text { Diferença entre } \\
\text { valores }\end{array}$ & difv & $\begin{array}{l}\text { Valor absoluto da diferença entre o valor } \\
\text { homologado e o estimado. }\end{array}$ \\
\hline Tempo em dias & diftempo & $\begin{array}{l}\text { É a diferença em dias entre a data de início e a data } \\
\text { de término de cada pregão. }\end{array}$ \\
\hline Modalidade & dmodal & $\begin{array}{l}\text { Variável dummy. Assume } 1 \text { se o pregão é eletrônico } \\
\text { ou } 0 \text { caso seja presencial. }\end{array}$ \\
\hline Itens frustrados & dfrustrados & $\begin{array}{l}\text { Variável dummy. Assume valor } 1 \text { se o pregão possuiu } \\
\text { algum item frustrado ou valor } 0 \text { caso contrário. }\end{array}$ \\
\hline Ano & d2016 & $\begin{array}{l}\text { Variável dummy. Assume valor } 1 \text { se o pregão foi } \\
\text { concluído em } 2016 \text { ou valor } 0 \text { caso contrário. }\end{array}$ \\
\hline Setor de saúde & dsaude & $\begin{array}{l}\text { Variável dummy. Assume valor } 1 \text { se os itens licitados } \\
\text { são da área da saúde ou valor } 0 \text { caso contrário. }\end{array}$ \\
\hline Setor de alimentos & daliment & $\begin{array}{l}\text { Variável dummy. Assume valor } 1 \text { se os itens licitados } \\
\text { são da área de alimentos ou valor } 0 \text { caso contrário. }\end{array}$ \\
\hline Setor de construção & dconstr & $\begin{array}{l}\text { Variável dummy. Assume valor } 1 \text { se os itens licitados } \\
\text { são da área de construção ou valor } 0 \text { caso contrário. }\end{array}$ \\
\hline Setor de educação & deduc & $\begin{array}{l}\text { Variável dummy. Assume valor } 1 \text { se os itens licitados } \\
\text { são da área da educação ou valor } 0 \text { caso contrário. }\end{array}$ \\
\hline
\end{tabular}

Fonte: elaboração própria.

A divisão dos pregões em cinco setores foi executada conforme descrito na Tabela 2:

\section{Tabela 2 | Divisão dos pregões em setores}

\begin{tabular}{ll}
\hline Setor & Características \\
\hline Saúde & $\begin{array}{l}\text { Produtos e serviços utilizados em situações médicas, hospitalares, } \\
\text { odontológicas, entre outras. }\end{array}$ \\
\hline Alimentos & $\begin{array}{l}\text { Produtos e serviços destinados à alimentação em escolas, creches e } \\
\text { centros de atendimento de turno integral, entre outros. }\end{array}$ \\
\hline Construção & Produtos e serviços destinados à construção civil ou obras. \\
\hline Educação & Produtos e serviços para fins educativos em escolas. \\
\hline Outros & $\begin{array}{l}\text { Todos os demais produtos e serviços que não foram classificados em } \\
\text { um dos quatro setores acima relacionados. }\end{array}$ \\
\hline
\end{tabular}

Fonte: elaborado pelos autores. 
A partir da classificação das variáveis e da divisão dos itens licitados em setores, observou-se que o setor de saúde, entre os setores específicos, foi a área que teve maior participação nos pregões municipais no período avaliado, atingindo os percentuais de 33\% em 2016 e 18\% em 2017. Os itens referentes ao setor de alimentos também se destacam, apresentando um total de participação de 13\% em 2016 e 17\% em 2017. Dentro dessa divisão, também foram constatados índices notáveis de 5\% em 2016 e 12\% em 2017 em pregões do setor de construção, bem como 9\% em 2016 e 2017 em pregões do setor de educação.

Os demais setores, classificados dentro da nomenclatura "Outros", individualmente não tiveram números expressivos, mas em sua totalidade, dentro dessa classificação singular, representaram 40\% e 44\% dos pregões de 2016 e 2017, respectivamente. Essas informações podem ser observadas na Tabela 3:

Tabela 3 | Total de pregões por setor e ano

\begin{tabular}{lcccccc}
\hline Setor & Ano 2016 & $\%$ ano 2016 & Ano 2017 & \% ano 2017 & Total & \% Total \\
\hline Saúde & 72 & 33 & 67 & 18 & 139 & 24 \\
\hline Alimentos & 29 & 13 & 64 & 17 & 93 & 16 \\
\hline Construção & 12 & 5 & 45 & 12 & 57 & 9 \\
\hline Educação & 19 & 9 & 34 & 9 & 53 & 9 \\
\hline Outros & 89 & 40 & 160 & 44 & 249 & 42 \\
\hline Total & $\mathbf{2 2 1}$ & $\mathbf{1 0 0}$ & $\mathbf{3 7 0}$ & $\mathbf{1 0 0}$ & $\mathbf{5 9 1}$ & $\mathbf{1 0 0}$ \\
\hline
\end{tabular}

Fonte: elaborado pelos autores.

A seguir apresentam-se as estatísticas descritivas dos dados utilizados para a composição amostral.

\subsection{Estatísticas descritivas}

A Tabela 4 apresenta as estatísticas descritivas das variáveis. Nela observa-se que, durante os anos de 2016 e 2017, o maior valor homologado foi de $R \$ 7.615 .894,32$, o valor mais alto estimado pela gestão municipal atingiu o montante de $R \$$ 7.741.266,00. Nesse sentido, é importante ressaltar que em apenas $18 \%$ dos pregões o valor homologado da licitação é maior que o valor médio $\mathrm{R} \$ 108.717,40$, algo que é similar ao 
valor estimado, sendo que em apenas $19 \%$ das licitações o valor estimado é superior à média desse indicador.

O valor unitário médio foi de $\mathrm{R} \$ 66.643,55$ reais, sendo que apenas $14.38 \%$ das licitações possuem um valor unitário mais elevado que a média. O item que possui o valor unitário mais elevado foi a contratação de um serviço de limpeza e conservação.

Ao se observar a diferença absoluta entre o valor homologado e o estimado, em $96 \%$ das licitações o valor estimado é superior ao homologado. Além disso, em aproximadamente $19 \%$ dos pregões a diferença absoluta é maior do que a estatística da média aritmética desse indicador, $\mathrm{R} \$$ 48.426,63. Em termos absolutos, a maior diferença entre essas duas variáveis é de $\mathrm{R} \$ 1.844 .513,00$.

Dentro dessa análise, dois pontos merecem ser salientados: i) a ocorrência dessa diferença se dá em virtude das estimativas do preço com uma margem para cima, por parte da administração pública; ii) o mecanismo gerado pelo processo de pregão, naturalmente, age como um condutor do processo de concorrência, estimulando a competição, fazendo com que o valor homologado seja menor do que o estimado.

Destaca-se que o prazo máximo de um pregão, entre os 591 observados, foi de 447 dias, tendo como média aproximadamente 84 dias. Em relação à variável dependente, o número máximo de ganhadores é de 18 , com um desvio de 1.41. Nesse sentido, em cerca de $49 \%$ das licitações o número de ganhadores foi maior que 1.93 .

Tabela 4 | Estatísticas descritivas das variáveis

\begin{tabular}{|c|c|c|c|c|c|}
\hline Variável & Observações & Média & $\begin{array}{l}\text { Desvio } \\
\text { padrão }\end{array}$ & Mínimo & Máximo \\
\hline vhomologado & 591 & $\mathrm{R} \$ 108,717.40$ & $\mathrm{R} \$ 418,914.00$ & $\mathrm{R} \$ 90.55$ & $\begin{array}{l}\mathrm{R} \$ \\
7,615,895.00\end{array}$ \\
\hline vestimado & 591 & $\mathrm{R} \$ 157,090.20$ & $\mathrm{R} \$ 500,687.90$ & $\mathrm{R} \$ 103.20$ & $\begin{array}{l}\mathrm{R} \$ \\
7,741,266.00\end{array}$ \\
\hline vunitario & 591 & $R \$ 66,643.55$ & $\mathrm{R} \$ 391,809.80$ & $\mathrm{R} \$ 24.55$ & $\begin{array}{l}\mathrm{R} \$ \\
7,615,895.00\end{array}$ \\
\hline difv & 591 & $\mathrm{R} \$ 48,426.63$ & $R \$ 143,286.00$ & $R \$ 0.00$ & $\begin{array}{l}\mathrm{R} \$ \\
1,844,513.00\end{array}$ \\
\hline
\end{tabular}




\begin{tabular}{llllll}
\hline Variável & Observações & Média & $\begin{array}{l}\text { Desvio } \\
\text { padrão }\end{array}$ & Mínimo & Máximo \\
\hline nganha & 591 & 1.93 & 1.41 & 1 & 18 \\
\hline diftempo & 591 & 83.77 & 81.83 & 0 & 447 \\
\hline dmodalidade & 591 & 0.97 & 0.16 & 0 & 1 \\
\hline d2016 & 591 & 0.37 & 0.48 & 0 & 1 \\
\hline dsaude & 591 & 0.24 & 0.42 & 0 & 1 \\
\hline daliment & 591 & 0.16 & 0.36 & 0 & 1 \\
\hline dconstr & 591 & 0.10 & 0.30 & 0 & 1 \\
\hline deduc & 591 & 0.09 & 0.29 & 0 & 1 \\
\hline doutros & 591 & 0.42 & 0.50 & 0 & 1 \\
\hline dfrustrados & 591 & 0.74 & 0.44 & 0 & 1 \\
\hline
\end{tabular}

Fonte: elaborado pelos autores.

Também é importante ressaltar que, dentro dos setores analisados, o setor 'Outros' apresenta a maior concentração de itens, representando cerca de $42 \%$ do total licitado. Já os setores de saúde e de alimentos representam, respectivamente, aproximadamente $24 \%$ e $16 \%$, destacando-se dentre os demais setores. Os setores de construção e educação representaram, nesta ordem, 10\% e 9\% do total de pregões de 2016 e 2017. Por fim, grande parte das licitações possuem itens frustrados, isto é, nem todos os itens foram licitados, o que representa um percentual de $74 \%$ das observações.

\subsection{Estratégia empírica}

O objetivo principal dos modelos de regressão para dados de contagem é estudar o comportamento de uma variável dependente $Y$, que se apresenta com valores discretos e não negativos, com base no comportamento de variáveis explicativas. A variável dependente usada apresenta essa característica, como pode ser observado no histograma apresentado na Figura 1. 
Figura 1 | Histograma do número de ganhadores por licitação

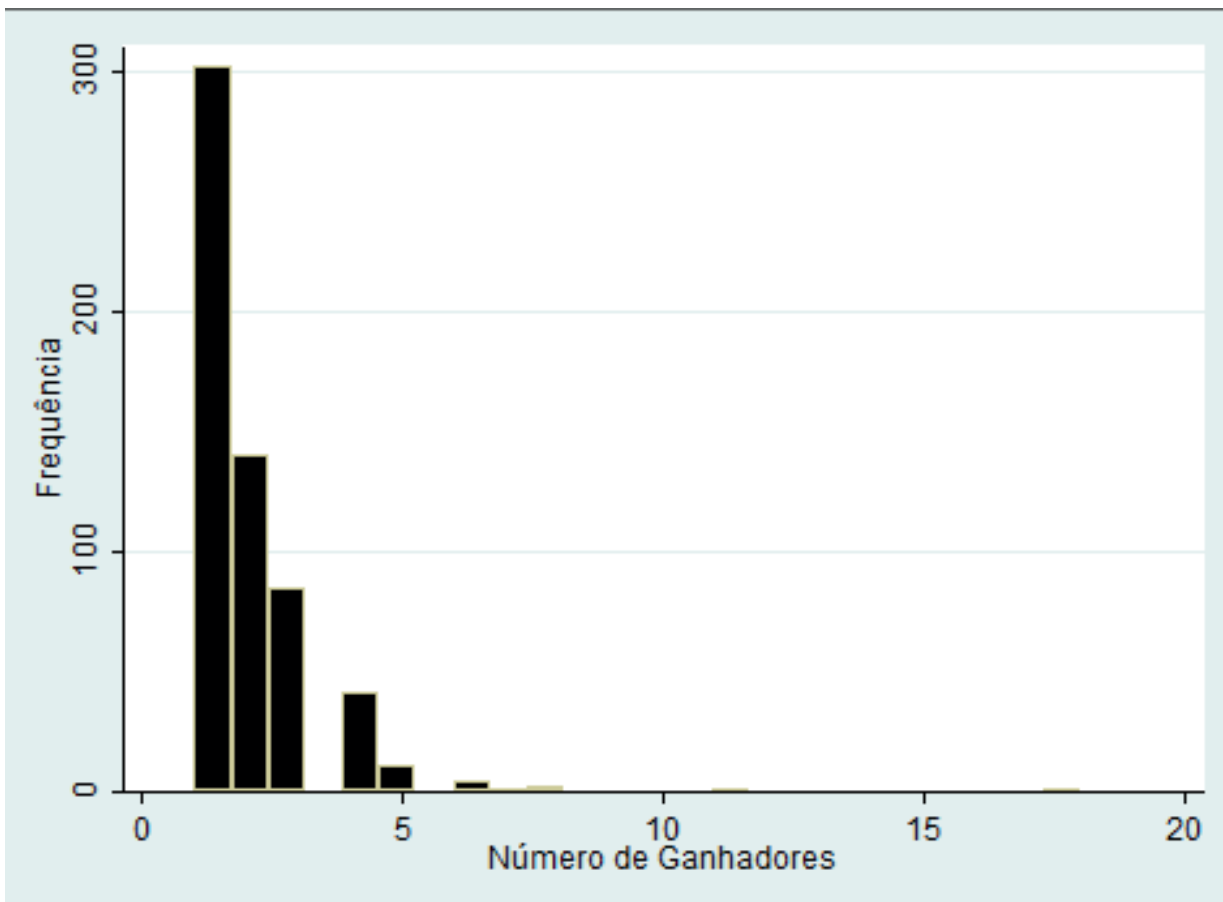

Fonte: elaborado pelos autores.

A distribuição de Poisson, para determinada observação $i(i=1,2, \ldots, n$, em que $n$ é o tamanho da amostra), possui a probabilidade de ocorrência de uma contagem $m$ em dada exposição, conforme segue:

$$
p(Y i=m)=\frac{e^{-\lambda} \cdot \lambda_{i}^{m}}{m !}, m=0,1,2, \ldots
$$

(1)

Nesta equação, $\lambda$ é o número esperado de ocorrências ou a taxa média estimada de incidência do fenômeno em estudo, para dada exposição. Nesse modelo, a média e a variância da variável devem ser iguais a $\lambda$ :

$$
E(y)=\operatorname{Var}(y)=\lambda
$$


Para Fávero e Belfiore (2017), caso essa equidispersão da distribuição de Poisson seja atendida, o modelo de Poisson poderá ser estimado da seguinte forma:

$$
\ln \ln \left(\hat{Y}_{i}\right)=\ln \ln \left(\lambda_{i}\right)=\alpha+\beta_{1} \cdot x_{1 i}+\beta_{2} \cdot x_{2 i}+\cdots+\beta_{k} \cdot x_{k i}
$$

Então, o número esperado de ocorrências em dada exposição para determinada observação i será:

$$
\lambda_{i}=e^{\left(\alpha+\beta_{1} \cdot x_{1 i}+\beta_{2} \cdot x_{2 i}+\cdots+\beta_{k} \cdot x_{k i}\right)}
$$

Portanto, as estimativas realizadas neste estudo serão efetuadas a partir da seguinte equação:

nganha $_{i}$

$=e^{\left(\beta_{0}+\beta_{1} \text { valor }+\beta_{2} \text { diftempo }+\delta_{1} \text { dmodal }+\delta_{2} \text { dfrustrados }+\delta_{3} d 2016+\sum_{i=4}^{8} \quad \delta_{i} \text { dsetor }+\mu\right)}$

(5)

Na próxima seção, serão apresentados os resultados e far-se-á a discussão.

\section{Resultados e discussão}

Para analisar o número de ganhadores das licitações na modalidade de pregão, foram estimados quatro modelos cujas variáveis explicativas são: i) valor homologado; ii) valor estimado; iii) valor unitário homologado; e iv) diferença entre valor homologado e valor estimado.

Essa análise é importante porque o valor do certame é um fator determinante do número de ganhadores do processo licitatório. Espera-se que esse parâmetro apresente uma correlação positiva com o número de ganhadores no processo licitatório. 
A Tabela 5, a seguir, mostra os resultados das regressões que possuem como controle o valor homologado:

Tabela 5 | Regressões para a variável dependente número de ganhadores, valor homologado

(1)

Ivhomologado

$0.10^{* * *}$

(0.02)

(2)

(3)

(4)

(5)

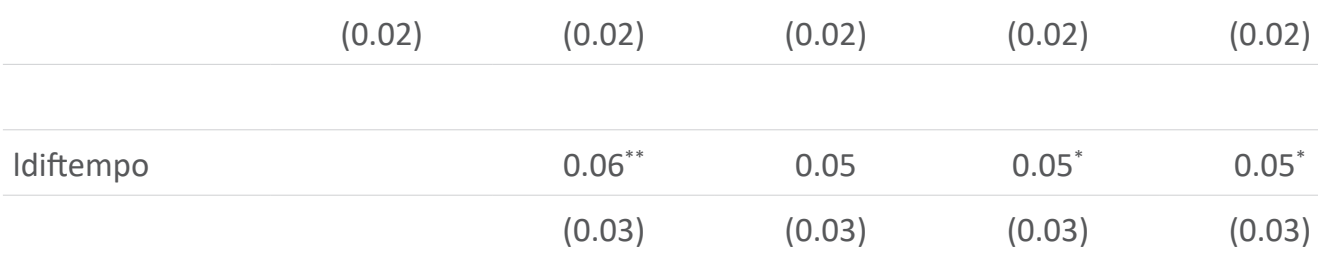

dfrustrados

$-0.39^{* *}$

$-0.39^{* * *}$

$-0.39^{* * *}$

(0.08)

(0.08)

(0.07)

d2016

0.07

0.07

(0.06)

(0.06)

dmodalidade

$-0.04$

(0.37)

\begin{tabular}{cccccc}
\hline Constante & -0.32 & $-0.58^{* * *}$ & $-0.46^{* *}$ & $-0.51^{* *}$ & -0.47 \\
\hline$N$ & $(0.20)$ & $(0.22)$ & $(0.20)$ & $(0.22)$ & $(0.32)$ \\
\hline 591 & 591 & 591 & 591 & 591
\end{tabular}

Fonte: elaborado pelos autores.

Notas: Erros Padrões Robustos entre parênteses, sendo * significativo a 10\%, ** significativo a $5 \%$ e *** significativo a $1 \%$.

Pode-se notar que, na Tabela 5, são apresentados cinco modelos, sendo que em cada um deles são adicionadas mais variáveis explicativas. Também é importante destacar que o valor homologado e a diferença de tempo estão em escala logarítmica, o que permite suavizar a série e reduzir a dispersão dos dados. Além disso, para realizar a interpretação 
dos coeficientes estimados, será utilizada a seguinte expressão: $\left(\exp \left(\beta^{*} \Delta x\right)-1\right) * 100$, onde que $\Delta x$ representa a variação de uma unidade na variável dependente de interesse.

Com base nas estimativas, pode-se perceber que o logaritmo do valor homologado se mostrou significativo em todos os modelos. Tomando como base os modelos (3) a (5), o aumento de uma unidade no logaritmo do valor homologado aumenta em $12.75 \%$ o número de ganhadores. No entanto, é difícil interpretar o que representa uma unidade no logaritmo do valor homologado. Pode-se utilizar a média dessa variável em logaritmo que é 9.8 e tomar o exponencial, o que resultaria em um montante de aproximadamente $\mathrm{R} \$$ $18.034,00$, isto é, um aumento de 9.8 no logaritmo do valor homologado resultaria em um acréscimo de, aproximadamente, 2.5 ganhadores.

Observa-se ainda que a diferença de tempo medida em dias apresentada na escala logarítmica também se mostrou significativa nos modelos (2), (4) e (5). Um aumento de uma unidade nessa variável resulta em um acréscimo entre 5\% a 6\% no número de ganhadores. Pode-se repetir o mesmo procedimento feito para o logaritmo do valor homologado, sendo que a média do logaritmo da diferença entre a data de lançamento e de homologação do edital é de 4.1, o que representa 60 dias. Assim, um aumento de 60 dias na diferença entre o lançamento do edital e a homologação dos vencedores implica no aumento de $25 \%$ a $27 \%$ no número de ganhadores.

A variável que representa se a licitação possuiu itens frustrados é sempre significativa nos modelos (3) a (5), e possui um coeficiente de, aproximadamente, -0.4 . Desse modo, se a licitação possuiu itens frustrados, isso representa um decréscimo de 32.93\% em média no número de vencedores.

Na sequência, far-se-á a análise incluindo os setores referentes a cada licitação. Optou-se por utilizar o modelo (5) com todas as variáveis explicativas, e então foram adicionadas as dummies setoriais. Esses resultados são apresentados na Tabela 6, como segue: 
Tabela 6 | Regressões para a variável dependente no de ganhadores, valor homologado, análise por setores
(1)
(2)
(3)
(4)
(5)

\begin{tabular}{|c|c|c|c|c|c|}
\hline \multirow[t]{2}{*}{ Ivhomologado } & $0.12^{* * *}$ & $0.12^{* * *}$ & $0.13^{* * *}$ & $0.12^{* * *}$ & $0.12^{* * *}$ \\
\hline & $(0.02)$ & $(0.02)$ & $(0.02)$ & $(0.02)$ & $(0.02)$ \\
\hline \multirow[t]{2}{*}{ dmodalidade } & 0.06 & -0.04 & -0.02 & -0.04 & 0.08 \\
\hline & $(0.33)$ & $(0.37)$ & (0.37) & $(0.37)$ & $(0.33)$ \\
\hline \multirow[t]{2}{*}{ Idiftempo } & $0.06^{*}$ & $0.05^{*}$ & $0.07^{* *}$ & $0.05^{*}$ & $0.07^{* *}$ \\
\hline & $(0.03)$ & $(0.03)$ & $(0.03)$ & $(0.03)$ & $(0.03)$ \\
\hline \multirow[t]{2}{*}{ dfrustrados } & $-0.35^{* * *}$ & $-0.39^{* * *}$ & $-0.40^{* * *}$ & $-0.40^{* * *}$ & $-0.36^{* * *}$ \\
\hline & $(0.06)$ & $(0.07)$ & $(0.07)$ & $(0.07)$ & $(0.06)$ \\
\hline \multirow[t]{2}{*}{ d2016 } & 0.06 & 0.06 & 0.06 & 0.07 & 0.06 \\
\hline & $(0.06)$ & $(0.06)$ & $(0.06)$ & $(0.06)$ & $(0.06)$ \\
\hline \multirow[t]{2}{*}{ Deduc } & $0.39^{* * *}$ & & & & $0.34^{* * *}$ \\
\hline & $(0.08)$ & & & & $(0.09)$ \\
\hline \multirow[t]{2}{*}{ Dconstr } & & -0.04 & & & -0.04 \\
\hline & & $(0.07)$ & & & $(0.08)$ \\
\hline \multirow[t]{2}{*}{ daliment } & & & $-0.21^{* * *}$ & & $-0.18^{* *}$ \\
\hline & & & $(0.07)$ & & $(0.07)$ \\
\hline \multirow[t]{2}{*}{ Dsaude } & & & & -0.07 & -0.05 \\
\hline & & & & $(0.05)$ & $(0.06)$ \\
\hline \multirow[t]{2}{*}{ constante } & $-0.67^{* *}$ & -0.46 & $-0.58^{*}$ & -0.42 & $-0.71^{* *}$ \\
\hline & $(0.29)$ & $(0.32)$ & $(0.32)$ & $(0.33)$ & $(0.29)$ \\
\hline$N$ & 591 & 591 & 591 & 591 & 591 \\
\hline
\end{tabular}

Fonte: elaborado pelos autores.

Notas: Erros Padrões Robustos entre parênteses, sendo * significativo a 10\%, ** significativo a $5 \%$ e ${ }^{* * *}$ significativo a $1 \%$. Utilizou-se o setor 'Outros' como o grupo de referência.

Ao se realizar a análise setorial, percebe-se que os coeficientes para o valor homologado, para diferença de tempo e a dummy de itens frustrados pouco se alteraram em relação às estimativas da Tabela 5. 
No modelo, onde é incluída a dummy para o setor de educação, nota-se que ele apresenta um efeito positivo de aproximadamente 0.4 . Isto é, se o item licitado é do setor de educação, o número de ganhadores aumenta em média em 49.2\%. Em contrapartida, observa-se que no modelo (3) da variável referente ao setor de alimentos apresentou um efeito negativo, sendo seu coeficiente estimado de - 0.21 . Assim, se a licitação se refere ao setor de alimentos, esse fato reduz em $18.94 \%$ o número de ganhadores.

Ao estimar-se a regressão incluindo dummies para todos os setores analisados, modelo (5), percebe-se que a magnitude dos setores de educação e alimentos é bastante próxima da análise individualizada por setor.

$\mathrm{Na}$ Tabela 7, foram feitas as estimativas trocando a variável dependente referente ao valor. Usou-se então o logaritmo do valor estimado de pregões realizados no Município de Pelotas.

Tabela 7 | Regressão para no de ganhadores, valor estimado
(1)
(2)
(3)
(4)
(5)

\begin{tabular}{|c|c|c|c|c|c|}
\hline \multirow[t]{2}{*}{ Ivestimado } & $0.11^{* * *}$ & $0.11^{* * *}$ & $0.13^{* * *}$ & $0.13^{* * *}$ & $0.13^{* * *}$ \\
\hline & $(0.02)$ & $(0.02)$ & $(0.02)$ & $(0.02)$ & $(0.02)$ \\
\hline \multirow[t]{2}{*}{ Idiftempo } & & $0.06^{* *}$ & 0.04 & $0.05^{*}$ & $0.05^{*}$ \\
\hline & & $(0.03)$ & $(0.03)$ & $(0.03)$ & $(0.03)$ \\
\hline \multirow[t]{2}{*}{ dfrustrados } & & & $-0.36^{* * *}$ & $-0.36^{* * *}$ & $-0.36^{* * *}$ \\
\hline & & & $(0.07)$ & $(0.07)$ & $(0.07)$ \\
\hline \multirow[t]{2}{*}{$d 2016$} & & & & 0.06 & 0.06 \\
\hline & & & & $(0.06)$ & $(0.06)$ \\
\hline
\end{tabular}

dmodalidade

\begin{tabular}{cccccc}
\hline constante & $-0.52^{* *}$ & $-0.76^{* * *}$ & $-0.62^{* * *}$ & $-0.66^{* * *}$ & $-0.61^{*}$ \\
& $(0.22)$ & $(0.23)$ & $(0.21)$ & $(0.22)$ & $(0.34)$ \\
$N$ & 591 & 591 & 591 & 591 & 591
\end{tabular}

Fonte: elaborado pelos autores.

Notas: Erros Padrões Robustos entre parênteses, sendo * significativo a $10 \%$, ** significativo a $5 \%$ e *** significativo a $1 \%$. Utilizou-se o setor 'Outros' como o grupo de referência. 
Nesse caso, o efeito do valor estimado para a variável dependente oscilou positivamente entre $11 \%$ e $13 \%$, isto é, um aumento de uma unidade no logaritmo do valor estimado acresce entre $11 \%$ a $13 \%$ no número de ganhadores de uma licitação. $\mathrm{A}$ média dessa variável em logaritmo é de 10.41, o que equivale em $\mathrm{R} \$ 33.189,00$. Então um aumento de aproximadamente 33 mil reais no valor estimado ocasiona o acréscimo de quase três novos vencedores.

Em relação ao logaritmo da diferença de tempo, o coeficiente estimado oscilou entre $5 \%$ e $6 \%$. Pode-se realizar a mesma análise observando um aumento na média do logaritmo da diferença de dias. 0 aumento de 60 dias entre a data de lançamento do edital e sua homologação acarreta em um aumento de $25 \%$ no número de ganhadores.

Ao avaliar a variável referente aos itens frustrados, os coeficientes desse indicador foram bastante similares aos da Tabela 5. Observa-se que, em média, se a licitação apresenta pelo menos um item frustrado, o impacto estimado no número de ganhadores é de uma redução de aproximadamente $30.23 \%$.

Na Tabela 8, realiza-se a análise setorial para o logaritmo do valor estimado. Os resultados são similares aos encontrados para o valor homologado, ou seja, apenas os setores de educação e de alimentação se mostraram significativos. No primeiro modelo, o fato de a licitação ser destinada para um item referente à educação aumenta em média em 44.5\% o número de ganhadores. Já o setor de alimentação, avaliado no modelo (3), apresenta um efeito negativo de, aproximadamente, $18 \%$ sobre a variável dependente. Pode-se notar que esses efeitos são reduzidos quando são testados todos os setores, conjuntamente, no modelo (5), ou seja, o coeficiente da dummy de educação cai em 0.05 e o do setor de alimentos em 0.03

Tabela 8 | Regressão para no de ganhadores, valor estimado, análise por setores

(3)

(4)

(5)

\begin{tabular}{lccccc}
\hline Ivestimado & $0.13^{* * *}$ & $0.13^{* * *}$ & $0.13^{* * *}$ & $0.12^{* * *}$ & $0.13^{* * *}$ \\
\hline & $(0.02)$ & $(0.02)$ & $(0.02)$ & $(0.02)$ & $(0.02)$ \\
\hline dmodalidade & 0.06 & -0.05 & -0.03 & -0.04 & 0.07 \\
\hline & $(0.34)$ & $(0.38)$ & $(0.38)$ & $(0.38)$ & $(0.34)$ \\
\hline
\end{tabular}




\begin{tabular}{|c|c|c|c|c|c|}
\hline & (1) & (2) & (3) & (4) & (5) \\
\hline \multirow[t]{2}{*}{ Ldiftempo } & $0.05^{*}$ & 0.05 & $0.07^{* *}$ & $0.05^{*}$ & $0.07^{* *}$ \\
\hline & $(0.03)$ & $(0.03)$ & $(0.03)$ & $(0.03)$ & $(0.03)$ \\
\hline \multirow[t]{2}{*}{ dfrustrados } & $-0.32^{* * *}$ & $-0.36^{* * *}$ & $-0.36^{* * *}$ & $-0.37^{* * *}$ & $-0.33^{* * *}$ \\
\hline & $(0.06)$ & $(0.07)$ & $(0.07)$ & $(0.07)$ & $(0.06)$ \\
\hline \multirow[t]{2}{*}{$d 2016$} & 0.06 & 0.06 & 0.06 & 0.07 & 0.06 \\
\hline & $(0.06)$ & $(0.06)$ & $(0.06)$ & $(0.06)$ & $(0.06)$ \\
\hline \multirow[t]{2}{*}{ Deduc } & $0.37^{* * *}$ & & & & $0.32^{* * *}$ \\
\hline & $(0.08)$ & & & & (0.09) \\
\hline \multirow[t]{2}{*}{ Dconstr } & & -0.04 & & & -0.04 \\
\hline & & $(0.07)$ & & & $(0.08)$ \\
\hline \multirow[t]{2}{*}{ Daliment } & & & $-0.20^{* * *}$ & & $-0.18^{* *}$ \\
\hline & & & $(0.07)$ & & $(0.07)$ \\
\hline \multirow[t]{2}{*}{ Dsaude } & & & & -0.07 & -0.05 \\
\hline & & & & $(0.05)$ & $(0.06)$ \\
\hline \multirow[t]{2}{*}{ Constante } & $-0.80^{* *}$ & $-0.61^{*}$ & $-0.72^{* *}$ & -0.56 & $-0.83^{* * *}$ \\
\hline & $(0.31)$ & $(0.34)$ & $(0.34)$ & $(0.34)$ & $(0.31)$ \\
\hline$N$ & 591 & 591 & 591 & 591 & 591 \\
\hline
\end{tabular}

Prossegue-se a análise mostrando os resultados estimados tendo como variável dependente o valor unitário homologado. Essa variável foi construída pela divisão do valor homologado pela quantidade de itens efetivamente comprados na licitação e é utilizada na escala logarítmica nas regressões. Nesse sentido, há três comentários a se fazer: i) a variável independente de interesse não apresentou significância estatística em nenhum dos modelos estimados; ii) a diferença de tempo entre data de lançamento do edital e a homologação dos resultados apresentou um efeito de $6 \%$ a $8 \%$ no acréscimo do número de ganhadores do certame; e iii) se a referida licitação apresentou pelo menos um item frustrado, informação medida pelo indicador dfrustado, em média, houve uma redução de $24.3 \%$ no número de ganhadores. 
Tabela 9 | Regressão para no de ganhadores, valor unitário

\begin{tabular}{|c|c|c|c|c|c|}
\hline & (1) & $(2)$ & (3) & (4) & (5) \\
\hline \multirow[t]{2}{*}{ Ivunitario } & -0.00 & -0.00 & 0.02 & 0.02 & 0.01 \\
\hline & $(0.01)$ & $(0.01)$ & $(0.02)$ & $(0.02)$ & $(0.01)$ \\
\hline \multirow[t]{2}{*}{ Idiftempo } & & $0.07^{* *}$ & $0.06^{* *}$ & $0.07^{* *}$ & $0.08^{* *}$ \\
\hline & & $(0.03)$ & $(0.03)$ & $(0.03)$ & $(0.03)$ \\
\hline \multirow[t]{2}{*}{ dfrustrados } & & & $-0.28^{* * *}$ & $-0.28^{* * *}$ & $-0.28^{* * *}$ \\
\hline & & & $(0.09)$ & $(0.09)$ & $(0.08)$ \\
\hline \multirow[t]{2}{*}{ d2016 } & & & & 0.05 & 0.06 \\
\hline & & & & $(0.07)$ & $(0.07)$ \\
\hline \multirow[t]{2}{*}{ dmodalidade } & & & & & -0.33 \\
\hline & & & & & $(0.43)$ \\
\hline \multirow[t]{2}{*}{ constante } & $0.68^{* * *}$ & $0.39^{* *}$ & $0.46^{* * *}$ & $0.42^{* *}$ & $0.74^{*}$ \\
\hline & $(0.11)$ & $(0.16)$ & $(0.15)$ & $(0.17)$ & $(0.41)$ \\
\hline$N$ & 591 & 591 & 591 & 591 & 591 \\
\hline
\end{tabular}

Tendo como alicerce inicial os resultados expressos na Tabela 9, pormenoriza-se essa avaliação incluindo-se os setores. A Tabela 10 resume os resultados para o valor unitário com a inclusão das dummies setoriais, como segue:

Tabela 10 | Regressão para no de ganhadores, valor unitário, análise por setores

\begin{tabular}{lccccc}
\hline & $(1)$ & $(2)$ & $(3)$ & $(4)$ & $(5)$ \\
\hline Ivunitario & 0.02 & 0.01 & 0.01 & 0.00 & 0.01 \\
\hline dmodalidade & $(0.01)$ & $(0.01)$ & $(0.01)$ & $(0.01)$ & $(0.01)$ \\
\hline & -0.20 & -0.33 & -0.31 & -0.31 & -0.20 \\
\hline Idiftempo & $(0.38)$ & $(0.43)$ & $(0.43)$ & $(0.43)$ & $(0.38)$ \\
\hline & $0.08^{* *}$ & $0.08^{* *}$ & $0.09^{* * *}$ & $0.07^{* *}$ & $0.09^{* * *}$ \\
\hline dfrustrados & $(0.03)$ & $(0.03)$ & $(0.03)$ & $(0.03)$ & $(0.03)$ \\
& & & & & $-0.27^{* * *}$ \\
\hline
\end{tabular}




\begin{tabular}{|c|c|c|c|c|c|}
\hline & (1) & $(2)$ & (3) & (4) & (5) \\
\hline \multirow[t]{2}{*}{$d 2016$} & 0.06 & 0.06 & 0.06 & 0.08 & 0.07 \\
\hline & $(0.07)$ & $(0.07)$ & $(0.07)$ & $(0.07)$ & $(0.07)$ \\
\hline \multirow[t]{2}{*}{ deduc } & $0.39^{* * *}$ & & & & $0.31^{* * *}$ \\
\hline & $(0.09)$ & & & & $(0.10)$ \\
\hline \multirow[t]{2}{*}{ dconstr } & & -0.02 & & & -0.04 \\
\hline & & $(0.07)$ & & & $(0.08)$ \\
\hline \multirow[t]{2}{*}{ daliment } & & & $-0.12^{*}$ & & $-0.13^{*}$ \\
\hline & & & $(0.07)$ & & $(0.08)$ \\
\hline \multirow[t]{2}{*}{ dsaude } & & & & $-0.20^{* * *}$ & $-0.17^{* *}$ \\
\hline & & & & $(0.06)$ & $(0.07)$ \\
\hline \multirow[t]{2}{*}{ constante } & 0.47 & $0.75^{*}$ & $0.68^{*}$ & $0.87^{* *}$ & 0.57 \\
\hline & $(0.35)$ & $(0.41)$ & $(0.40)$ & $(0.41)$ & $(0.35)$ \\
\hline$N$ & 591 & 591 & 591 & 591 & 591 \\
\hline
\end{tabular}

Os resultados das estimativas apresentadas na Tabela 10 são similares aos das regressões sem os controles setoriais. Os coeficientes das variáveis que medem a diferença de tempo apresentam uma magnitude de 7 a 9\%. Assim, ao se observar o efeito na média desse indicador, que equivale a 60 dias, o acréscimo no número de ganhadores seria de aproximadamente 33\%. Em relação à magnitude do coeficiente, o mesmo efeito ocorre com a dummy de itens frustrados. Em média, esse efeito é negativo e oscila entre 28 e 35\%. Ou seja, se há pelo menos um item frustrado, a licitação apresenta, em média, entre 28 e 35\% menos ganhadores, o que poderia impactar em uma menor concorrência.

Adicionalmente, o setor de educação apresenta um efeito positivo, de $50 \%$ no número de ganhadores. Em média, se o item licitado é caracterizado com um objeto destinado a fins educacionais, há $50 \%$ mais ganhadores do que se o item pertencesse a outro grupo. Um efeito inverso ocorre com os setores de alimentos (-11\%) e saúde (-20\%). No modelo (6), quando são utilizados todos os setores, mantendo-se como referência outros setores, o coeficiente das variáveis setoriais mantém o sinal, porém apresenta magnitude distinta. 
Como a última variável independente de interesse, na Tabela 11, considera-se o logaritmo do valor absoluto da diferença entre o valor homologado e o estimado. Usa-se o valor absoluto para evitar a perda de observações, levando-se em conta que o domínio da função logaritmo não permite valores negativos ou nulos. Essa variável mostrou-se significativa em todos os modelos, sendo que o aumento de uma unidade na mesma acarreta um acréscimo de $11 \%$ no número de ganhadores. Esse indicador tem como média 9.06, medido na escala logarítmica, o que implica $\mathrm{R} \$ \mathbf{8 . 6 0 4 , 0 0}$. Se a diferença entre o valor homologado e o valor estimado for desse montante, o efeito sobre o número de ganhadores é, em média, de 171\%, ou seja, de aproximadamente dois ganhadores.

Ainda, tem-se que a variável que indica se houve itens frustrados na licitação apresentou coeficientes parecidos em relação às estimativas anteriores, embora com menor magnitude. Em relação aos itens frustrados, o efeito permanece nos modelos (3) a (5) de $-23.67 \%$, como segue:

Tabela 11 | Regressão para no de ganhadores, diferença de valor

(1)

Ildifv

$0.11^{* * *}$

(0.01)

(2)

(3)

(4)

(5)

\begin{tabular}{|c|c|c|c|c|c|}
\hline Ildifv & $0.11^{* * *}$ & $0.11^{* * *}$ & $0.11^{* * *}$ & $0.11^{* * *}$ & $0.11^{* * *}$ \\
\hline & $(0.01)$ & $(0.01)$ & $(0.01)$ & $(0.01)$ & $(0.01)$ \\
\hline \multirow[t]{2}{*}{ Idiftempo } & & 0.04 & 0.03 & 0.03 & 0.04 \\
\hline & & $(0.03)$ & $(0.03)$ & $(0.03)$ & $(0.03)$ \\
\hline \multirow[t]{2}{*}{ dfrustrados } & & & $-0.27^{* * *}$ & $-0.27^{* * *}$ & $-0.27^{* * *}$ \\
\hline & & & $(0.07)$ & $(0.07)$ & $(0.07)$ \\
\hline \multirow[t]{2}{*}{$d 2016$} & & & & 0.04 & 0.05 \\
\hline & & & & $(0.06)$ & $(0.06)$ \\
\hline \multirow[t]{2}{*}{ dmodalidade } & & & & & -0.24 \\
\hline & & & & & $(0.41)$ \\
\hline \multirow[t]{2}{*}{ constante } & $-0.33^{* * *}$ & $-0.48^{* * *}$ & $-0.27^{*}$ & $-0.30^{*}$ & -0.08 \\
\hline & $(0.11)$ & $(0.15)$ & $(0.15)$ & $(0.16)$ & $(0.38)$ \\
\hline$N$ & 591 & 591 & 591 & 591 & 591 \\
\hline
\end{tabular}

Fonte: elaborado pelos autores.

Notas: Erros Padrões Robustos entre parênteses, sendo * significativo a 10\%, ** significativo a $5 \%$ e *** significativo a $1 \%$. 
Adicionalmente, apresenta-se a Tabela 12, na qual se realizaram as regressões para o número de ganhadores, verificando o impacto da diferença de valor e dos setores dos itens licitados. Assim como nas anteriores, apenas a dummy do setor de educação apresentou um efeito positivo na variável dependente. O fato de o setor ser de educação aumenta em média $41 \%$ o número de ganhadores. A variável referente ao setor de alimentação apresentou um coeficiente negativo, com um impacto de $14 \%$ sobre o número de ganhadores. No modelo (4), a dummy relacionada ao setor de saúde se mostrou significativa, sendo que, se o objeto licitado pertence a esse setor, isso reduz o número de ganhadores em, aproximadamente, 9.5\%. Contudo, esse efeito se manteve quando se realizaram as estimativas para todos os setores conjuntamente.

Tabela 12 | Regressão para no de ganhadores, diferença de valor, análise por setor
(1)
(2)
(3)
(4)
(5)

\begin{tabular}{|c|c|c|c|c|c|}
\hline \multirow[t]{2}{*}{ Ildifv } & $0.10^{* * *}$ & $0.11^{* * *}$ & $0.11^{* * *}$ & $0.10^{* * *}$ & $0.10^{* * *}$ \\
\hline & $(0.01)$ & $(0.01)$ & $(0.01)$ & $(0.01)$ & $(0.01)$ \\
\hline \multirow[t]{2}{*}{ dmodalidade } & -0.14 & -0.24 & -0.24 & -0.23 & -0.13 \\
\hline & $(0.38)$ & $(0.41)$ & $(0.41)$ & $(0.41)$ & $(0.38)$ \\
\hline \multirow[t]{2}{*}{ Idiftempo } & 0.05 & 0.04 & $0.06^{*}$ & 0.04 & $0.06^{*}$ \\
\hline & $(0.03)$ & $(0.03)$ & $(0.03)$ & $(0.03)$ & $(0.03)$ \\
\hline \multirow[t]{2}{*}{ dfrustrados } & $-0.24^{* * *}$ & $-0.27^{* * *}$ & $-0.27^{* * *}$ & $-0.29^{* * *}$ & $-0.25^{* * *}$ \\
\hline & $(0.06)$ & $(0.07)$ & $(0.07)$ & $(0.07)$ & $(0.06)$ \\
\hline \multirow[t]{2}{*}{ d2016 } & 0.05 & 0.04 & 0.04 & 0.06 & 0.05 \\
\hline & $(0.06)$ & $(0.06)$ & $(0.06)$ & $(0.06)$ & $(0.06)$ \\
\hline \multirow[t]{2}{*}{ deduc } & $0.34^{* * *}$ & & & & $0.28^{* * *}$ \\
\hline & $(0.08)$ & & & & $(0.09)$ \\
\hline \multirow[t]{2}{*}{ dconstr } & & -0.04 & & & -0.05 \\
\hline & & $(0.07)$ & & & $(0.08)$ \\
\hline \multirow[t]{2}{*}{ daliment } & & & $-0.15^{* *}$ & & $-0.14^{* *}$ \\
\hline & & & $(0.06)$ & & $(0.07)$ \\
\hline
\end{tabular}


(1)

$\begin{array}{lc} & \\ \text { constante } & -0.24 \\ & (0.35) \\ N & 591\end{array}$

(2)

$-0.07$

(0.38)

591
(3)

$-0.13$

(0.38)

591
(4)

(0.05)

$-0.22$

591

Fonte: elaborado pelos autores.

Notas: Erros Padrões Robustos entre parênteses, sendo * significativo a 10\%, ** significativo a $5 \%$ e *** significativo a $1 \%$. Utilizou-se o setor 'Outros' como o grupo de referência.

Em suma, com base na análise dos efeitos estimados para o número de vencedores de uma licitação, pode-se observar que o valor do licitado apresenta um efeito positivo sobre o número de ganhadores. Esse efeito se manteve estatisticamente para três das quatro variáveis, que foram usadas para medir o valor monetário da licitação.

Pode-se inferir, então, que licitações com maior valor atraem um maior número de empresas, o que incentiva a competição e acarreta um número maior de vencedores do certame. Além disso, o valor unitário do item licitado não se mostrou estatisticamente significativo para explicar o número de ganhadores, o que pode sugerir que: i) as empresas preferem participar de licitações em que o valor do objeto é maior; ii) itens com o custo muito pequeno, isto é, preço unitário baixo, precisam ser vendidos em larga quantidade para propiciar uma lucratividade maior, nesse caso o valor total (preço $\times$ quantidade vendida) é uma informação mais interessante para as empresas; e iii) há relativamente um número menor de produtores para esses itens, o que pode acarretar em uma participação mais baixa.

A diferença de tempo entre a data de lançamento do edital e a homologação dos vencedores também apresentou um efeito positivo, mas não estatisticamente significativo em todas as regressões. Desse modo, se a diferença de tempo é maior, isso pode significar que o edital permanece aberto por um intervalo de tempo maior, o que possibilita que mais empresas possam participar do concurso licitatório, o que também poderia induzir um aumento da concorrência.

Outro fator que se mostrou importante foi o fato de a licitação ter itens frustrados. A relação entre essa variável e o número de vencedores parece direta. Se forem licitados 30 itens e, entre esses, considerarmos que 10 itens foram frustrados por não terem sido 
apresentadas ofertas, certamente haverá um menor número de vencedores. Tendo como base a média dos coeficientes das estimativas acima, o fato de a licitação ter pelo menos um item frustrado reduz em média $30 \%$ o número de vencedores.

Na análise dos setores, as compras feitas para itens referentes à educação mostraram-se positivas para o aumento do número de ganhadores; porém, para o setor de alimentação apresentou um efeito contrário. Pode-se destacar que o setor de saúde se apresentou significativo apenas em uma das regressões.

Nesse sentido, os resultados encontrados estão alinhados com os estudos de Faria et al. (2011), Nóbrega (2015) e Controladoria Geral da União (2017), no sentido de que a modalidade de pregão pode ser um bom mecanismo para atrair a participação de um maior número de empresas no certame.

É importante destacar que estimativas mais acuradas poderiam ser obtidas usandose a razão entre o número de vencedores e o total de participantes do certame, o que certamente tornaria a análise e os resultados mais precisos. Para isso, contudo, seria preciso obter informações complementares que extrapolariam o escopo deste artigo.

De qualquer modo, os resultados aqui reportados contêm indícios suficientes de que o pregão é um modelo licitatório que precisa ser aprimorado no sentido de melhor controle de qualidade dos itens licitados, tendo em vista que unicamente critério do menor preço pode não ser suficiente para garantir a relação custo versus benefício, das compras públicas.

\section{Considerações finais}

A eficiência no gasto público e na gestão de compras públicas é um problema com o qual muitos gestores estão se deparando na atual conjuntura da economia brasileira. Desse modo, municípios, estados e União fazem uso de pregões para a aquisição de bens e serviços comuns pelo menor preço, pois essa modalidade de compra pública se mostra rápida e econômica, e, portanto, mais eficiente quando comparada a outras. 
A Lei do Pregão Eletrônico, criada a partir da conversão da Medida Provisória no 2.206 de 2000 na Lei no 10.520 de 2002, é um dos instrumentos criados para promover uma maior concorrência entre os possíveis participantes do processo licitatório (BRASIL, 2000a, 2002a).

Nesse sentido, o presente trabalho buscou analisar as características específicas de pregões realizados pela Prefeitura Municipal de Pelotas, nos períodos de 2016 e 2017, visando identificar os possíveis determinantes da concorrência licitatória, medida pelo número de empresas vencedoras das licitações realizadas sob a forma de pregão, sendo ele presencial ou eletrônico.

Para realizar essa tarefa, foram coletadas informações de 591 pregões do banco de dados da página virtual do Tribunal de Contas do Estado do Rio Grande do Sul (TCE/ RS), denominada LicitaCon Cidadão. Com base nessas informações, aplicou-se o modelo de regressão de Poisson e fez-se a análise econométrica, usando como proxy para a concorrência do processo licitatório o número de ganhadores de cada pregão.

Com base nas estimativas, o valor do produto licitado apresentou um efeito positivo sobre o número de ganhadores. Esse efeito se manteve estatisticamente significativo para três das quatro variáveis: valor homologado, valor estimado e a diferença absoluta entre o valor estimado e o homologado. Esses indicadores foram usados para medir o valor monetário da licitação, e, por isso, pode-se inferir que licitações com maior valor atraem um maior número de empresas, o que incentiva a competição e acarreta um número maior de vencedores do certame.

Assim, o único indicador que não se apresentou significativo foi o valor unitário homologado, reforçando a hipótese de que as empresas desejam participar de certames em que o valor total é maior, e que o preço unitário do item não afeta diretamente essas firmas no interesse pelo processo licitatório.

A diferença de tempo entre a data de lançamento do edital e a homologação dos vencedores também apresentou um efeito positivo, mas não foi estatisticamente significativo em todas as regressões. Contudo, a intuição oriunda desse resultado é que, se a diferença de tempo é maior, o que pode significar que o edital permanece aberto por um intervalo de tempo maior, esse fato possibilita que mais empresas possam participar do concurso licitatório, o que também poderia induzir um aumento da concorrência. 
Outro fator importante foi o fato de a licitação ter itens frustrados. A relação entre essa variável e o número de vencedores parece direta, pois, se forem licitados 30 itens e, entre esses, considerarmos que 10 itens foram frustrados por não terem sido apresentadas ofertas, então haverá um menor número de vencedores.

Ainda, na análise de setores, os pregões realizados para itens referentes à educação mostraram-se positivos para o aumento do número de ganhadores; porém, para o setor de alimentação, apresentaram um efeito contrário. Também o setor de saúde se apresentou significativo apenas em uma das regressões.

As estimativas indicam que licitações com o valor monetário mais elevado apresentam um maior número de ganhadores, sendo esse um possível canal para o aumento da concorrência. Em outras palavras, se, diante das possibilidades de aquisição da administração pública for possível realizar uma compra com um valor mais elevado, como, por exemplo, agregando mais itens, esse fato atrairia um maior número de empresas para participarem do certame.

Ademais, o tempo entre a abertura do edital e a homologação dos resultados é um ponto-chave. Embora ocorram algumas aquisições em que o órgão público necessite de urgência para a realização da compra, as estimativas apontam que um prazo mais dilatado poderia ser importante para permitir, por exemplo, a maior divulgação do edital e possibilitar a participação de um número maior de empresas.

Em suma, para uma nova agenda de pesquisa, seria interessante analisar os pregões realizados pelo Município de Pelotas para os anos que se seguem a partir daqui, no intuito de testar se os resultados futuros irão se confirmar ou representam apenas uma tendência temporária. Outro fator que poderia aprimorar a análise quantitativa seria a construção da variável de concorrência medida pela razão entre número de vencedores e o total de empresas participantes do certame. Além disso, seria importante incluir outros órgãos municipais que não se encontram presentes neste estudo, para a apresentação de resultados mais abrangentes e completos. 


\section{Referências}

ALENCAR, Eduardo José de. Estudo sobre aspectos gerenciais do pregão: uma análise gerencial de sua utilização pela administração pública do Estado de Pernambuco. 2006. Tese (Doutorado). Programa de Pós-Graduação em Gestão e Pública p/ o Desenvolvimento do Nordeste, Universidade Federal de Pernambuco, Recife, 2006. Disponível em: https://repositorio.ufpe.br/ handle/123456789/6978. Acesso em: 26 set. 2020

AZEVEdo, Vânia Cristina Rennó. Estudo e avaliação da eficiência do processo de compras públicas: caso Embrapa. 2011. 49f. Monografia (Bacharelado em Administração) - Universidade de Brasília, Palmas, 2011. Disponível em: https://bdm.unb.br/handle/10483/3400. Acesso em: 26 set. 2020

BRANDÃo, Franklin Torres. Eficiência na gestão das compras públicas: um estudo de caso da modalidade pregão eletrônico nos processos licitatórios do Instituto Federal de Educação, Ciência e Tecnologia do Sertão Pernambucano. 2016. 157f. Dissertação (Mestrado Profissional em Gestão de Processos Institucionais) - Centro de Ciências Humanas, Letras e Artes, Universidade Federal do Rio Grande do Norte, Natal, 2016. Disponível em: https://repositorio.ufrn.br/ handle/123456789/21930. Acesso em: 26 set. 2020

BRASIL. [Constituição (1988)]. Constituição da República Federativa do Brasil de 1988. Brasília: Presidência da República, [2016]. Disponível em: http://www.planalto.gov.br/ccivil_03/ Constituicao/Constituicao.htm. Acesso em: 14 fev. 2020.

Lei n. 8.666, de 21 de junho de 1993 (Lei Geral das Licitações). Regulamenta o art. 37, inciso XXI, da Constituição Federal, institui normas para licitações e contratos da administração Pública e dá outras providências. Brasília: Presidência da República, [2016]. Disponível em: http:// www.planalto.gov.br/ccivil_03/Leis/L8666cons.htm. Acesso em: 28 jan. 2020.

Medida Provisória 2.026, de 4 de Maio de 2000. Institui, no âmbito da União, modalidade de licitação denominada pregão, para aquisição de bens e serviços comuns. Brasília: Presidência da República, [2000a]. Disponível em: http://www.planalto.gov.br/ccivil_03/mpv/Antigas/2026. htm. Acesso em: 04 ago. 2020.

Decreto 3.697, de 21 de dezembro de 2000. Regulamenta o parágrafo único do art. 2은 da Medida Provisória no 2.026-7, de 23 de novembro de 2000, que trata do pregão por meio da utilização de recursos de tecnologia da informação. Brasília: Presidência da República, [2000b]. Disponível em: https://www.planalto.gov.br/ccivil_03/decreto/d3697.htm. Acesso em: 02 mar. 2020.

Lei n. 10.520, de 17 de julho de 2002. Institui, no âmbito da União, Estados, Distrito Federal e Municípios, nos termos do art. 37, inciso XXI, da Constituição Federal, modalidade de licitação denominada pregão, para aquisição de bens e serviços comuns, e dá outras providências. Brasília: Presidência da República, [2002a]. Disponível em: www.planalto.gov.br/ccivil_03/ leis/2002/I10520.htm. Acesso em: 28 jan. 2020.

Decreto 5.450, de 31 de maio de 2005. Regulamenta o pregão, na forma eletrônica, para aquisição de bens e serviços comuns, e dá outras providências. Brasília: Presidência da República, [2005]. Disponível em: www.planalto.gov.br/ccivil_03/_ato2004-2006/2005/decreto/d5450.htm. Acesso em: 02 mar. 2020. 
Lei 12.529, de 30 de novembro de 2011. Estrutura o Sistema Brasileiro de Defesa da Concorrência e dá outras providências. Brasília: Presidência da República, [2011]. Disponível em: planalto.gov.br/ccivil_03/_ato2011-2014/2011/lei/l12529.htm. Acesso em: 04 ago. 2020.

Decreto 10.024, de 20 de setembro de 2019. Regulamenta a licitação, na modalidade pregão, na forma eletrônica. Brasília: Presidência da República, [2019] Disponível em: http:// www.planalto.gov.br/ccivil_03/_Ato2019-2022/2019/Decreto/D10024.htm. Acesso em: 04 ago. 2020.

Controladoria Geral da União (CGU). Nota Técnica no 1.081 2017. Disponível em: https://www. gov.br/cgu/pt-br/assuntos/noticias/2017/07/cgu-divulga-estudo-sobre-eficiencia-dos-pregoesrealizados-pelo-governo-federal/nota-tecnica-no-1-081-2017-cgplag-dg-sfc.pdf/@@download/ file/nota-tecnica-no-1-081-2017-cgplag-dg-sfc.pdf. Acesso em: 27 mar. 2020.

DIAS, Mariana Dattoli Gouveia. O problema das compras de baixa qualidade decorrentes da utilização do pregão eletrônico. Brasília-DF: Conteúdo Jurídico, 2014. Disponível em: https:// conteudojuridico.com.br/consulta/Artigos/39405/o-problema-das-compras-de-baixa-qualidadedecorrentes-da-utilizacao-do-pregao-eletronico. Acesso em: 20 set. 2020.

FARIA, Evandro Rodrigues; Ferreira, Marco Aurélio Marques; SANTOS, Lucas Maia; SILVEIRA, Suely de Fátima Ramos. Pregão eletrônico versus pregão presencial: estudo comparativo de redução de preços e tempo. Revista de Contabilidade do Mestrado em Ciências Contábeis da UERJ, v. 16, n. 1, p. 47-62, 2011.

FÁVERo, Luiz Paulo Lopes; BelfiORE, Patrícia. Manual de análise de dados: estatística e modelagem multivariada com excel, SPSS e Stata. Rio de Janeiro-RJ: Elsevier, 2017.

FURTUNA, Marcos Rogério. Pregão eletrônico: economia, celeridade e transparência nas contratações públicas. 2015. 81f. Monografia (Bacharelado em Direito) - Universidade de Brasília, Brasília, 2015. Disponível em: https://bdm.unb.br/handle/10483/10941. Acesso em: 20 set. 2020.

MAS-ColelL, Andreu; Whinston, Michael; Green, Jerry. Microeconomic Theory. Nova lorque, Estados Unidos: Oxford University Press,1995.

NóBREGA, Marcos. O processo de mudança dos mecanismos das compras governamentais no Brasil: vantagens e riscos da contratação integrada. Revista do Tribunal de Contas do Estado de Minas Gerais, v. 33, n. 2, p. 23-37, 2015. Disponível em: https://revista.tce.mg.gov.br/revista/ index.php/TCEMG/article/viewFile/99/69. Acesso em: 28 fev. 2020.

PenA, Cláudia Brito; Felicidade, Rafaela Suzana de Nazaré; Monteiro, Josué. Licitação Por Pregão Eletrônico: economicidade, celeridade e transparência na Secretaria de Estado da Fazenda do Pará - SEFA. In: VII SEGET - SIMPósIO de EXCELÊNCIA EM GESTÃo E TECNOLOGIA, 21., 2010. Anais eletrônicos [...]. Resende-RJ: Associação Educacional Dom Bosco, 2010. Disponível em: https:// www.aedb.br/seget/arquivos/artigos10/295_TCC\%20Simposio\%20de\%20Gestao\%20e\%20 Excelencia\%20em\%20Tecnologia.pdf. Acesso em: 8 fev. 2020.

RIo GRANDE Do SUl. Resolução no 1.050 de 2015. Dispõe sobre o envio e a disponibilização, por meio do Sistema de Licitações e Contratos - LicitaCon, de dados, informações e documentos relativos a licitações e contratos administrativos dos poderes, órgãos e entidades jurisdicionados do Tribunal de Contas do Estado do Rio Grande do Sul. Porto Alegre: Governo do Estado do Rio 
Grande do Sul [2015]. Disponível em: https://atosoficiais.com.br/originais/rs/tcers/RES-10502015-TCERS-RS.zip. Acesso em: 06 ago. 2020.

Resolução 1.073 de 2017. Altera o inciso II do artigo 5o da Resolução no 1050, de 04 de novembro de 2015, que dispõe sobre o envio e a disponibilização, por meio do Sistema de Licitações e Contratos - LicitaCon, de dados, informações e documentos relativos a licitações e contratos administrativos dos poderes, órgãos e entidades jurisdicionados do Tribunal de Contas do Estado do Rio Grande do Sul. Porto Alegre: Governo do Estado do Rio Grande do Sul [2015]. Disponível em: <https://atosoficiais.com.br/originais/rs/tcers/RES-1073-2017-TCERS-RS.zip . Acesso em: 06. ago. 2020.

SILVA, Kássia Barcelos; BRITo, Daniel Higa Souza. A eficiência do sistema de registro de preço na modalidade pregão eletrônico na administração pública. Revista Facthus de Administração e Gestão, v. 1, n. 2, p. 68-88, 2017. Disponível em: http://publicacoes.facthus.edu.br/index.php/ administracao/article/download/137/126. Acesso: 20 set. 2020.

Tribunal de Contas do Estado do Rio Grande do Sul (TCE/RS). Licitacon cidadão. Disponível em: http://www1.tce.rs.gov.br/aplicprod/f?p=50500:1:::NO::.. Acesso: 29 jan. 2020.

WOOLDRIDGE, Jeffrey. Econometric analysis of cross section and panel data. Londres, Inglaterra: MIT Press, 2010.

\section{Rodrigo Nobre Fernandez}

(D) https://orcid.org/0000-0001-8596-2898

Doutor em Economia (ênfase Economia Aplicada) pela Universidade Federal do Rio Grande do Sul. Professor do Departamento de Economia da Universidade Federal de Pelotas.

Pelotas - RS

E-mail: rodrigonobrefernandez@gmail.com

\section{Thaís Garcia Ribas}

(D) https://orcid.org/0000-0002-6605-5237

Bacharel em Ciências Econômicas e Licenciada em Língua Espanhola e Literaturas de Língua Espanhola ambas pela Universidade Federal de Pelotas. Agente Administrativa na Secretaria Municipal de Administração e Recursos Humanos da Prefeitura Municipal de Pelotas.

E-mail: thatatapel@yahoo.com.br 